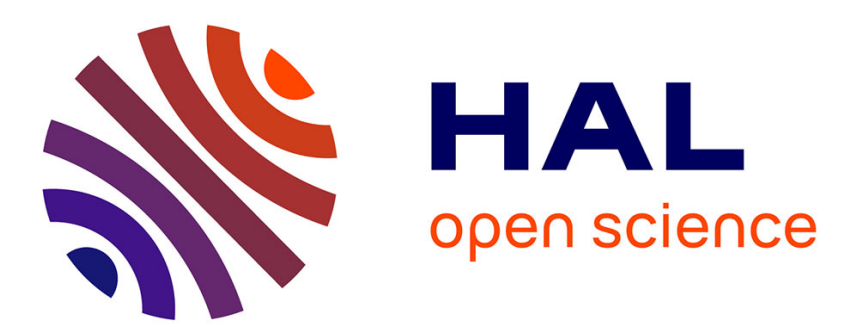

\title{
Chemically Fueled Three-State Chiroptical Switching Supramolecular Gel with Temporal Control
}

Enzo Olivieri, Guilhem Quintard, Jean-Valère Naubron, Adrien Quintard

\section{To cite this version:}

Enzo Olivieri, Guilhem Quintard, Jean-Valère Naubron, Adrien Quintard. Chemically Fueled ThreeState Chiroptical Switching Supramolecular Gel with Temporal Control. Journal of the American Chemical Society, 2021, 143 (32), pp.12650 - 12657. 10.1021/jacs.1c05183 . hal-03346635

\section{HAL Id: hal-03346635 https://hal.science/hal-03346635}

Submitted on 16 Sep 2021

HAL is a multi-disciplinary open access archive for the deposit and dissemination of scientific research documents, whether they are published or not. The documents may come from teaching and research institutions in France or abroad, or from public or private research centers.
L'archive ouverte pluridisciplinaire HAL, est destinée au dépôt et à la diffusion de documents scientifiques de niveau recherche, publiés ou non, émanant des établissements d'enseignement et de recherche français ou étrangers, des laboratoires publics ou privés. 


\title{
Chemically Fueled Three-State Chiroptical Switching Supramolecular Gel with Temporal Control
}

\author{
Enzo Olivieri, Guilhem Quintard, Jean-Valère Naubron, and Adrien Quintard*
}

\begin{abstract}
The recent discovery of temporally controlled gels opens broad perspectives to the field of smart functional materials. However, to obtain fully operative systems, the design of simple and robust gels displaying complex functions is desirable. Herein, we fuel dissipative gelating materials through iterative additions of trichloroacetic acid (TCA). This simple fuel enables to switch over time an acid/base-dependent commercially available amino acid gelator/DBU combination between three distinct states (anionic, cationic, and neutral), while liberating volatile $\mathrm{CO}_{2}$ and $\mathrm{CHCl}_{3}$ upon fuel consumption. Of interest, the anionic resting state of the system is obtained through trapping of 1 equiv of $\mathrm{CO}_{2}$ through the formation of a carbamate. The system is tunable, robust, and resilient over time with over 25 consecutive sol-gel-sol cycles possible without significant loss of properties. Most

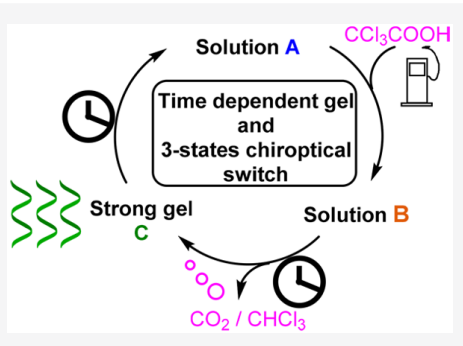
importantly, because of the chiral nature of the amino acid gelator, the system features chiroptical switching properties moving reversibly between three distinct states as observed by ECD. The described system considerably enhances the potential of smart molecular devices for logic gates or data storage by adding a time dimension based on three states to the gelating materials. It is particularly simple in terms of chemical components involved, but it enables sophisticated functions.
\end{abstract}

\section{INTRODUCTION}

Our modern societies rely on elaborated technologies for progress, and developing supramolecular smart materials possessing well-defined complex functions could unveil innovative applications. ${ }^{1}$ In this context, inserting a time dimension could further enhance the potential of smart materials. Mimicking nature, the design of self-assembled supramolecular structures able to transiently change properties over time through a stimulus represents a young field of research with great potential. ${ }^{2}$ Nature's out-of-equilibrium machinery is built on complex dynamic settings able to perform a variety of crucial biological functions by using the free energy of a fuel such as ATP. ${ }^{2}$ By transposing such principles, the design of purely synthetic self-assembled systems could open broad perspectives for the development of adaptive smart materials such as dissipative gels able to switch reversibly over time from solution to the gel state. However, these efforts are hampered by the inherent difficulty at designing efficient dynamic autonomous systems not relying on complex multiple enzymatic setting. ${ }^{3}$ As a result, despite their potential, a limited set of transformations were applied in these reversible time-responsive gelations, narrowing materials potential functions. ${ }^{4,5}$ The difficulty at designing new systems is due to the challenge associated with the control of the reactions at the origin of the reversible selfassembly (gelation) phenomena and the fuel consumption. These processes must be to some extent compatible, and to be operative upon fuel addition, the rate of self-assembly upon the stimuli should be faster than the rate of fuel consumption. Finally and of utmost importance in view of the operability ensuring a large number of sol-gel-sol cycles, these cycles should not disturb the chemical composition of the solution to avoid the system deactivation. This is difficult since in most known cases an additional reagent embedded in the initial solution reacts to consume the fuel so that its concentration steadily decreases, while on the other side a large amount of undesired waste is accumulating. Given the limited set of systems available, for now, only a handful of applications have been identified for such dissipative gels. ${ }^{2 g}$ In other words, new supramolecular dissipative materials with innovative functions of increased complexity are highly desirable.

Supramolecular chiroptical switches have recently attracted considerable interest due to their potential applications for instance in logic gates devices or data storage. ${ }^{6}$ However, while some of the known dissipative gels are based on chiral molecules possessing two types of chiroptical signals, they are not resilient over multiple cycles. ${ }^{7}$ Until now, chiroptical switches, typically using circular dichroism (CD) or circularly polarized luminescence (CPL) measurements, have been relying on two types of switching phenomena: the on/off states; the significant variation of the measured value, for instance its increase/ decrease in absolute value; its variations in positive/negative sign. To enhance the possibilities offered by chiroptical switches, 
moving from the two-state approach to a three-state approach is a promising direction. It was only recently that George's group reported a multienzymatic setting generating a chiroptical switch between three states. ${ }^{8}$ However, a simple purely synthetic system providing malleable materials with comparable chiroptical properties is yet unknown. To push functional materials to a new dimension, herein, we report a robust and resilient synthetic system for dissipative gels with three-state chiroptical switching properties. This strategy uses simple chiral amino acid $\mathbf{2}$ as gelator in combination with 1,8-diazabicyclo[5.4.0] undec-7-ene (DBU) and trichloroacetic acid (TCA) as chemical fuel (Figure 1).

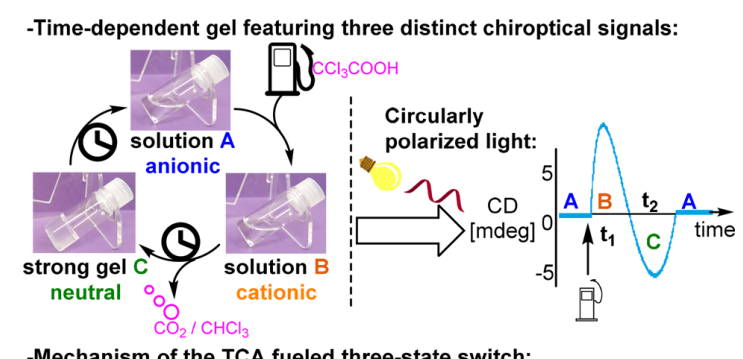

-Mechanism of the TCA fueled three-state switch:

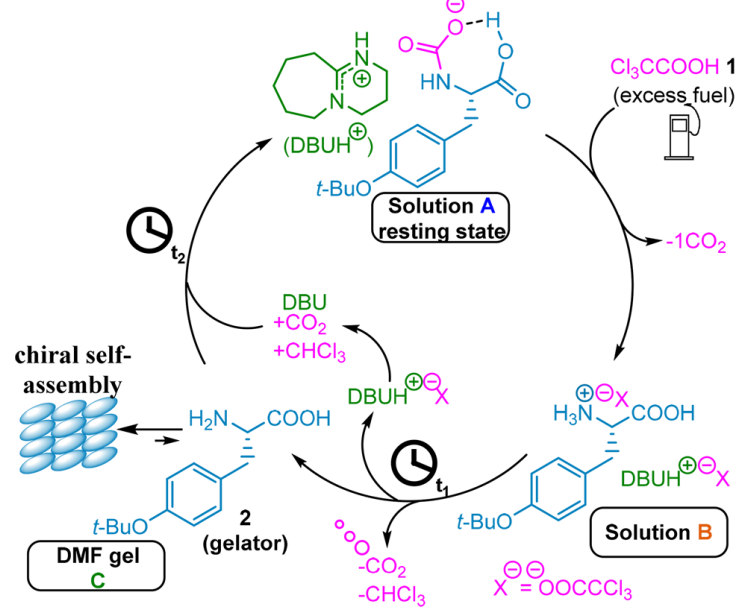

Figure 1. Three-state TCA-fueled functional material.

TCA is known to undergo thermal or base promoted decomposition generating $\mathrm{CO}_{2}$ gas and volatile $\mathrm{CHCl}_{3}$, thus avoiding waste accumulation. ${ }^{9,10}$ It has notably been used by the group of Takata, Leigh, or recently Kim to switch between two states (neutral and cationic) in molecular motors or in a temporary host-guest complex. ${ }^{9}$ We hypothesized that this cheap molecule could act as an optimum fuel for the next generation of dissipative gels based on three distinct anionic, cationic, and neutral states (Figure 1). For such purpose, we draw our attention to the combination between chiral amino acids, known as potential acid/base-dependent gelators, ${ }^{11,12}$ and a strong base such as DBU potentially able to catalyze TCA decarboxylation and induce amino acid deprotonation. We discovered that from the anionic amino acid solution A where the circular dichroism (CD) signal is nearly null, TCA addition induces protonation of the amines generating solution $\mathrm{B}$ with a strong positive $\mathrm{CD}$ signal. Upon amino acid and $\mathrm{DBU}$ catalyzed decarboxylation of TCA, volatile $\mathrm{CO}_{2}$ and $\mathrm{CHCl}_{3}$ are liberated over time $\left(t_{1}\right)$, forming the temporary strong supramolecular neutral gel $\mathrm{C}$ with negative $\mathrm{CD}$ signal. Finally, regeneration over time $\left(t_{2}\right)$ of the anionic solution A closes the cycle. Interestingly, careful mechanistic investigations revealed that in the anionic resting state solution $\mathrm{A}, 1$ equiv of $\mathrm{CO}_{2}$ is trapped by the amino acid/DBU system through carbamate formation (Figure 1). ${ }^{13}$ This carbamate instantaneously liberates 1 equiv of $\mathrm{CO}_{2}$ upon addition of the fuel. Of importance, the chiroptical switching material is fully operative, limits waste accumulation, and as a result can achieve over $25 \mathrm{sol}-\mathrm{gel}-$ sol cycles through successive fuel additions. Overall, the system is particularly simple in terms of the molecular components it involves but enables to obtain sophisticated functions.

\section{RESULTS AND DISCUSSION}

Gel System Optimization, Time Concentration Dependence, and Kinetics. Among amino acids, commercially available $O$-tert-butyl-L-tyrosine (2) was recently applied as potent low molecular weight $(\mathrm{MW}=237 \mathrm{~g} / \mathrm{mol})$ organogelator under neutral conditions. ${ }^{12}$ At the onset, to validate the potential of $\mathbf{2}$ as a $\mathrm{pH}$-dependent organogelator, we added excess TCA to a DMF suspension of $2(1 \% \mathrm{w} / \mathrm{v}) .{ }^{14}$ We were delighted to observe that upon standing at room temperature a strong gel was spontaneously generated within $10 \mathrm{~min}$ (vial inversion method, Table 1). This gel was stable for weeks at room temperature and

Table 1. System Optimization through the Vial Inversion Method $^{a}$

$\begin{array}{cccccc}\text { basic additive: } & \text { none } & \mathrm{Et}_{3} \mathrm{~N} & \text { piperidine } & \text { MTBD } & \text { DBU } \\ \text { sol-gel transition } & \text { yes } & \text { yes } & \text { yes } & \text { yes } & \text { yes } \\ \text { gel-sol transition } & \text { no } & \text { no } & \text { no } & \text { yes } & \text { yes }\end{array}$

${ }^{a}$ Conditions: $2(42 \mu \mathrm{M})$, basic additive $(75 \mu \mathrm{M})$, DMF ( $\left.1 \mathrm{~mL}\right), 20$ ${ }^{\circ} \mathrm{C}$. Addition of TCA $(240 \mu \mathrm{M})$. Sol-gel-sol transition observed through vial inversion method.

even after $4 \mathrm{~h}$ heating at $60^{\circ} \mathrm{C}$. To trigger the desired sol-gelsol transition, we then screened different organic bases (Table 1). In the presence of weak bases such as piperidine or $\mathrm{Et}_{3} \mathrm{~N}$, after gelation, no return to the solution was observed even after $24 \mathrm{~h}$. The absence of solubilization of the gel is attributed to their known inability to stabilize amines- $-\mathrm{CO}_{2}$ adducts. ${ }^{13}$ In sharp contrast, by use of stronger bases stabilizing such carbamates ${ }^{13}$ such as 7-methyl-1,5,7-triazabicyclo[4.4.0] dec-5-ene (MTBD) or DBU, TCA addition triggered the strong gel formation in $\sim 5$ min, leading back to a solution after 2 min. Furthermore, after adding again TCA, another sol-gel-sol cycle was observed demonstrating the potential of these strong bases to trigger the desired complete cycle. Given the close sol-gel-sol transitions observed between these two bases, DBU was chosen for further studies.

Having identified the appropriate dissipative gelation combination, we next had an insight into the tunability of the sol-gel-sol system and on the role of the different constituents. For such purpose, the turbidity of the gels was estimated by measuring the absorption at $400 \mathrm{~nm}$ and after performing an initial sol-gel-sol cycle corresponding to the formation of the carbamate resting state of the system (Figure 2) ${ }^{4 c, k}$ Monitoring the absorption enables to determine the time upon which a turbid gel (defined above $50 \%$ of the maximal absorbance) is generated $\left(t_{1}\right)$ and the time before its deformation $\left(t_{2}\right)$. As anticipated, at a fixed $120 \mu \mathrm{M}$ concentration in TCA, modulating the DBU concentration considerably impacted the time before gelation $\left(t_{1}\right)$ (Figure 2 , top). From a gel generated in 
a)

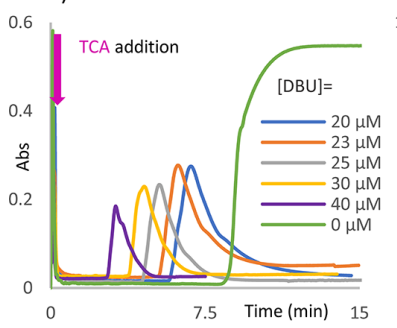

c)

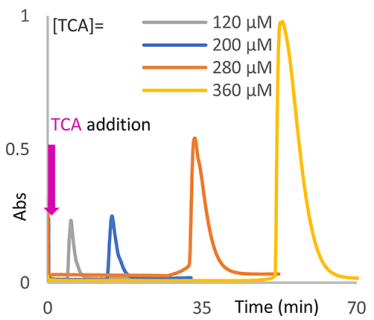

b)

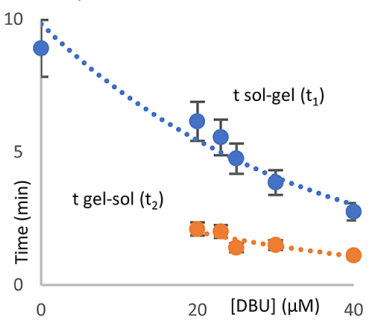

d)

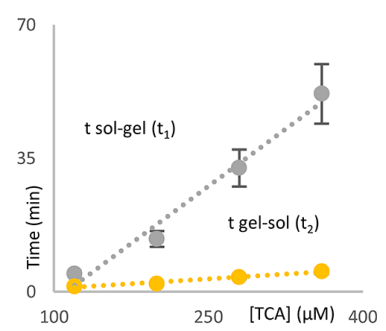

Figure 2. (a) Turbidity of the sol-gel-sol and time [DBU] dependence. $2(21 \mu \mathrm{M})$, TCA $(120 \mu \mathrm{M})$, in $2 \mathrm{~mL}$ of DMF at $20^{\circ} \mathrm{C}$. (b) Plot of sol-gel $\left(t_{1}\right)$ and gel-sol $\left(t_{2}\right)$ as a function of [DBU]. (c) Turbidity of the sol-gel-sol and time [TCA] dependence. $2(21 \mu \mathrm{M})$, DBU $(25 \mu \mathrm{M})$, in $2 \mathrm{~mL}$ of DMF at $20{ }^{\circ} \mathrm{C}$. (d) Plot of $t_{1}$ and $t_{2}$ as a function of [TCA]. All measurements performed after an initial solgel-sol cycle using $90 \mu \mathrm{M}$ [TCA]. Turbidity monitored through UV dispersion at $400 \mathrm{~nm}$.

$<3$ min at $[\mathrm{DBU}]=40 \mu \mathrm{M}$ (purple curve), gel formation $\left(t_{1}\right)$ was delayed to $6 \mathrm{~min}$ at $[\mathrm{DBU}]=20 \mu \mathrm{M}$ (blue). In the absence of DBU, gelation occurred with an increase in $t_{1}$ to $9 \mathrm{~min}$ (green). Altogether, these results indicate that DBU and 2 both contribute to the fuel decarboxylation (see also Table S1). The DBU concentration also impacted the time length $\left(t_{2}\right)$ of the gel, doubling from $1 \mathrm{~min}$ at $[\mathrm{DBU}]=40 \mu \mathrm{M}$ to $2 \mathrm{~min}$ at $[\mathrm{DBU}]=20$ $\mu \mathrm{M}$. In addition, when decreasing the DBU concentration from 40 to $20 \mu \mathrm{M}$, the time before going back to a clear solution is even further increased from 2.0 to $6.3 \mathrm{~min}$ (see Figure S11). When reducing the amount of DBU further $(16 \mu \mathrm{M})$, a brake in the degelation process is observed with a gel lasting $\sim 29 \mathrm{~h}$ as determined through vial inversion. Finally, as already mentioned, in the absence of DBU, a gel stable over time $(>1$ month) is observed. These results confirm the role of DBU over gel destruction which is linked to the formation of the carbamate resting state solution $\mathrm{A}$.

Varying the amount of TCA also modulated both $t_{1}$ and $t_{2}$ (Figure 2, bottom). From [TCA] $=120 \mu \mathrm{M}$ (gray) to $[\mathrm{TCA}]=$ $360 \mu \mathrm{M}$ (yellow), the sol-gel time $\left(t_{1}\right)$ increased from 4.7 to $51.0 \mathrm{~min}$. This is consistent with the role of TCA, which needs to be consumed prior to gel formation. In parallel, the gel-sol time $\left(t_{2}\right)$ also increased from 1.4 to $5.3 \mathrm{~min}$ upon similar increase in the amount of TCA, concomitant with an increase in the turbidity. We hypothesized that the $\mathrm{CO}_{2}$ generated upon the decarboxylation might explain this behavior. This was confirmed by bubbling $\mathrm{CO}_{2}$ through solution A prior to the sol-gel-sol cycle, resulting in an increase in $t_{2}$ (see Figure S13). This effect might be due to the reversible trapping of $\mathrm{DBU}$ by $\mathrm{CO}_{2}$ prior to carbamate formation, delaying the degelation process at higher $\mathrm{CO}_{2}$ concentrations. ${ }^{13}$

Given the strong gaps in $\mathrm{p} K_{\mathrm{a}}$ between the different components $\left(\mathrm{p} K_{\mathrm{a}}:\right.$ DBU $\gg$ amino acid $\gg$ TCA), the sol-

gel-sol process can also be easily visualized through the addition of small amount of acid/base sensitive dyes (Figure 3, Figures

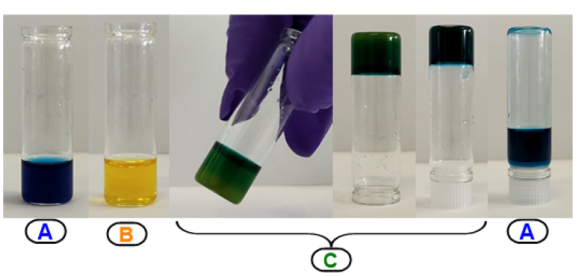

Figure 3. Visualization of the sol-gel-sol cycle through the use of acid/base sensitive dyes DMF solution. Conditions: $2(42 \mu \mathrm{M})$, DBU $(54 \mu \mathrm{M}), 1 \mathrm{~mL}$ of DMF acid/base sensitive dyes solution. The solgel-sol cycle was performed by using $60 \mu \mathrm{L}$ of TCA solution $(C=0.65$ $\mathrm{mg} / \mu \mathrm{L}, 237 \mu \mathrm{M})$ after an initiation cycle with $45 \mu \mathrm{L}$ of TCA solution $(C=0.65 \mathrm{mg} / \mu \mathrm{L}, 179 \mu \mathrm{M})$.

S17 and 18). From the blue solution A where the color results from excess DBU, addition of TCA induces an instantaneous formation of yellow solution $\mathrm{B}$, corresponding to protonated DBU and amino acid. The solution remains yellow during TCA consumption until a green color appears. This corresponds to the liberation of neutral amino acid in the system, triggering a rapid self-assembly. Gelation occurs at the onset of the color change, suggesting that as soon as enough amino acid is present in the neutral form, gelation rapidly occurs while the more basic $\mathrm{DBU}$ is still fully protonated. The color in the gel state $(\mathrm{C})$ then evolves with DBU liberation upon remaining TCA decarboxylation, providing a green then blue gel, moving back again to a solution upon carbamate $\mathrm{A}$ formation through $\mathrm{CO}_{2}$ trapping.

Chiroptical Properties. To probe the chiroptical properties and further understand the different steps of the gel assembly/ disassembly cycles, we followed the process using UV and electronic circular dichroism (ECD) spectroscopies which are particularly efficient to monitor the dynamics of these kinds of processes (Figure 4). UV and ECD spectra were measured in
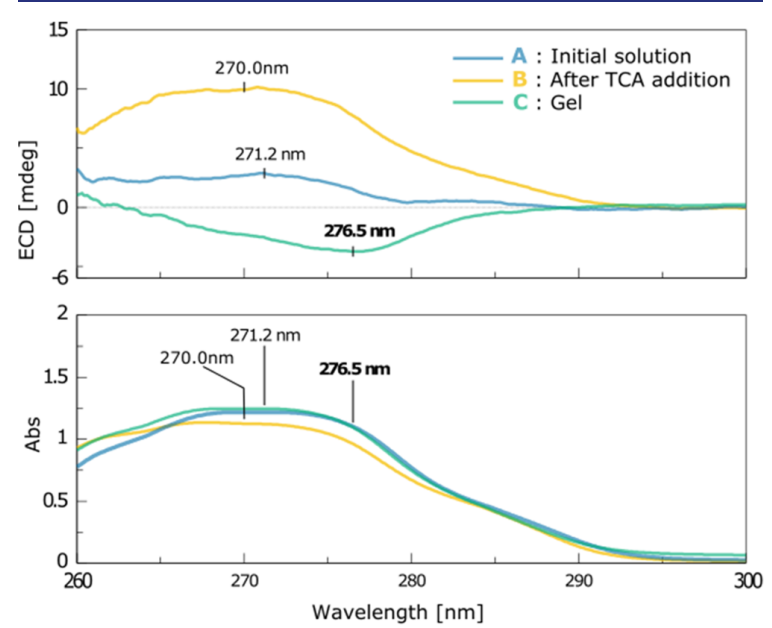

Figure 4. ECD (top) and UV (bottom) spectra of the system before TCA addition and after gel disassembly (blue). After TCA addition (orange) and gel (green) measured in DMF during sol-gel-sol cycle. Conditions: $2(8.4 \mu \mathrm{mol})$, DBU $(18.8 \mu \mathrm{mol})$ in $0.4 \mathrm{~mL}$ of DMF at 20 ${ }^{\circ} \mathrm{C}$. Addition of $9 \mu \mathrm{L}$ of TCA solution $(C=0.65 \mathrm{mg} / \mu \mathrm{L}, 35.8 \mu \mathrm{mol})$ in DMF. Acquisition: $100 \mathrm{~nm} / \mathrm{min}$. 


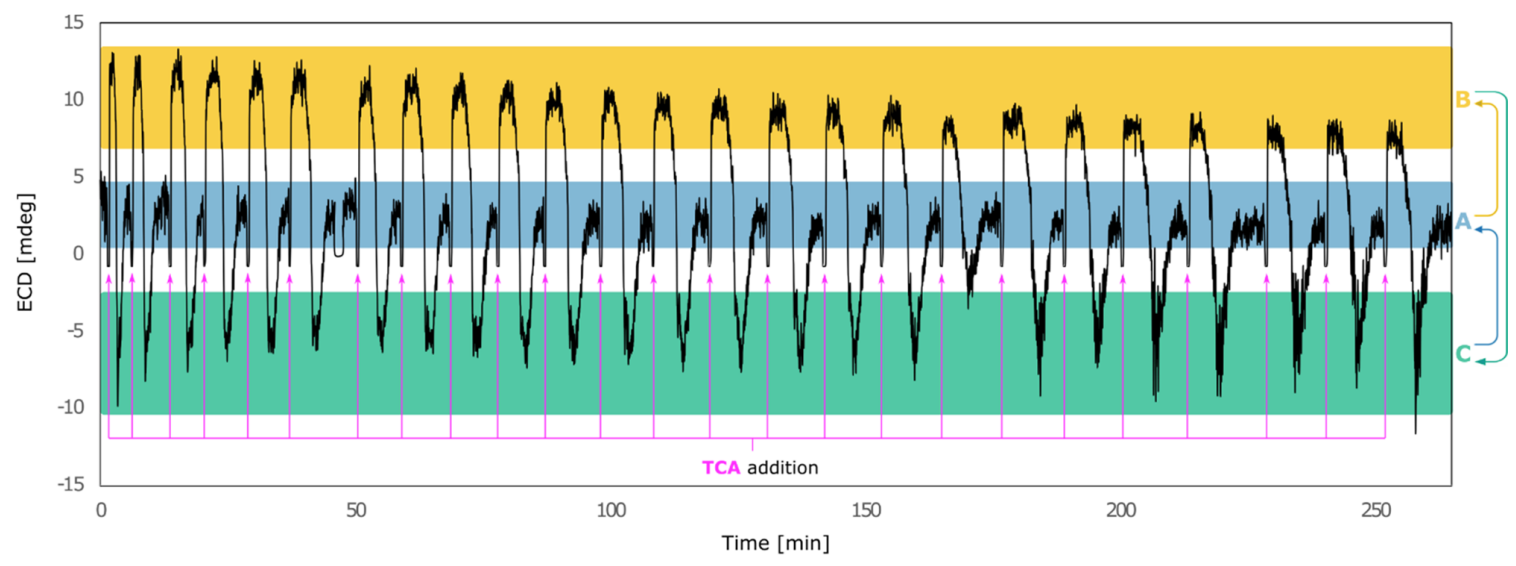

Figure 5. Time course of ECD at $279 \mathrm{~nm}$ over multiple sol-gel-sol cycles upon successive TCA additions.

parallel on two channels of the same spectrometer (JACSO J815) after an initial sol-gel-sol cycle. Figure 4 shows UV and their corresponding ECD spectra measured over time after TCA addition to the system (see the Supporting Information for details). These spectra reveal three striking states: the solution B in which TCA solution has just been added (orange spectrum), the gel C (green spectrum), and the solution A after disassembly of the gel, which is also the initial solution before TCA addition (blue spectrum). The UV spectra of the gel and of the solution after gel disassembly are quite close, whereas a small hypsochromic shift is measured when the TCA is added to the solution. Moreover, we notice the presence of a shoulder around $280 \mathrm{~nm}$ that can be attributed to the $-\mathrm{COOH}$ function which is generally characterized by a band around $270 \mathrm{~nm}$. On the corresponding ECDs the three states are clearly distinguishable. Before TCA addition (or after the gel disassembly), the spectrum of the solution is characterized by a flat and large slightly positive band around $271 \mathrm{~nm}$. Once TCA is added, the intensity of the positive band increases strongly with a weak hypsochromic shift. Finally, during the gel assembly process the positive band progressively becomes negative. This change of sign is accompanied by a clear bathochromic shift from 270 to $276 \mathrm{~nm}$. Upon gel deformation, the initial solution (blue spectrum) is formed again.

Given these remarkable changes in the $\mathrm{CD}$ signal observed for the three states, we probe the potential of the dissipative system as chiroptical switch over multiple cycles upon successive additions of TCA (Figure 5). Gratifyingly, the three states were observed reliably over 25 consecutive cycles. During a cycle, the $\mathrm{CD}$ signal switches from a close to zero value to a strong positive signal upon TCA addition and a strong negative signal upon gel formation before going back to the initial value upon gel disassembly. The repetition of the cycles does not affect the succession of the three different signals in ECD that characterize each of the three states of the system. Because of dilution through the addition of DMF solutions of TCA and the aging of the solution notably through partial $\mathrm{CO}_{2}$ and chloroform accumulation, small variations of the measured intensity are observed (see Figure S20), which can be explained by the increasing dominance of dispersion phenomena in the measurements. Similarly, multiple sol-gel-sol cycles could be reliably repeated by using the vial inversion method (see Table S2). This uncommonly reliable switch highlights the great operability and robustness of the dissipative chiroptical system, a crucial parameter for further applications.

The high sensitivity of the photomultiplicator detector used on the ECD spectrometer allows to measure small intensity variations with high accuracy. This provided a better understanding of the switching gelation mechanism through the analysis of the evolution of the ECD and UV bands as a function of time during the cycle at $279 \mathrm{~nm}$, a wavelength enabling to observe the individual events during the whole process. The overall sol-gel-sol cycle is defined through seven individual steps representing the chemical reactions and supramolecular processes occurring for one cycle (Figure 6). After introducing TCA to the initial solution, during TCA consumption (step 1), we observe a positive plateau in ECD and a very slight decrease of the absorbance in the UV. It is followed in the UV by two linear increases in absorbance with different durations and slopes (steps 2 and 3). In ECD, the same behavior is observed but with a decrease of the intensity which becomes negative in

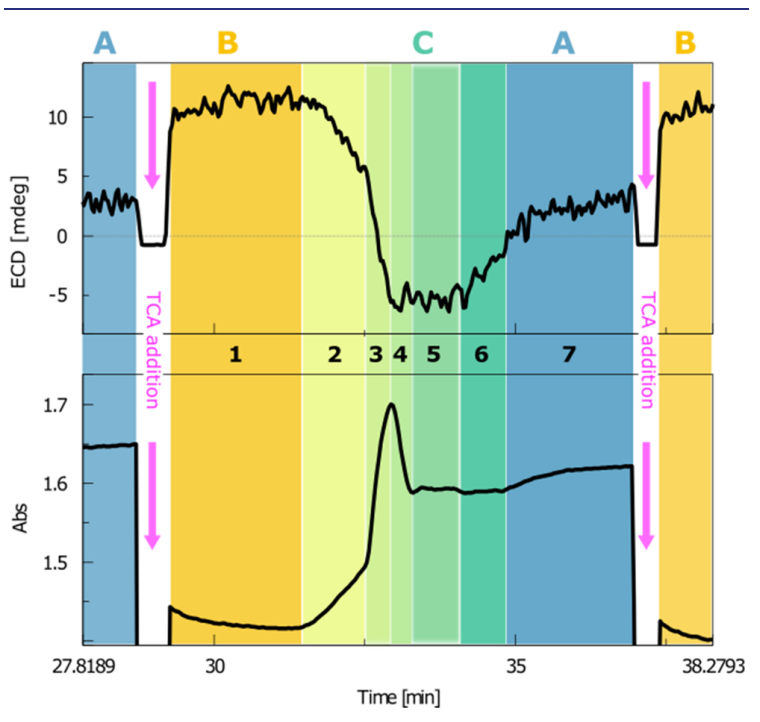

Figure 6. ECD (top) and UV (bottom) - COOH band intensity at 279 $\mathrm{nm}$ with respect to time during cycle 5 . Conditions: $2(8.4 \mu \mathrm{mol})$, DBU $(18.8 \mu \mathrm{mol})$ in $0.4 \mathrm{~mL}$ of DMF at room temperature. Addition of $9 \mu \mathrm{L}$ of TCA solution $(C=0.65 \mathrm{mg} / \mu \mathrm{L}, 35.8 \mu \mathrm{mol})$ in DMF. 


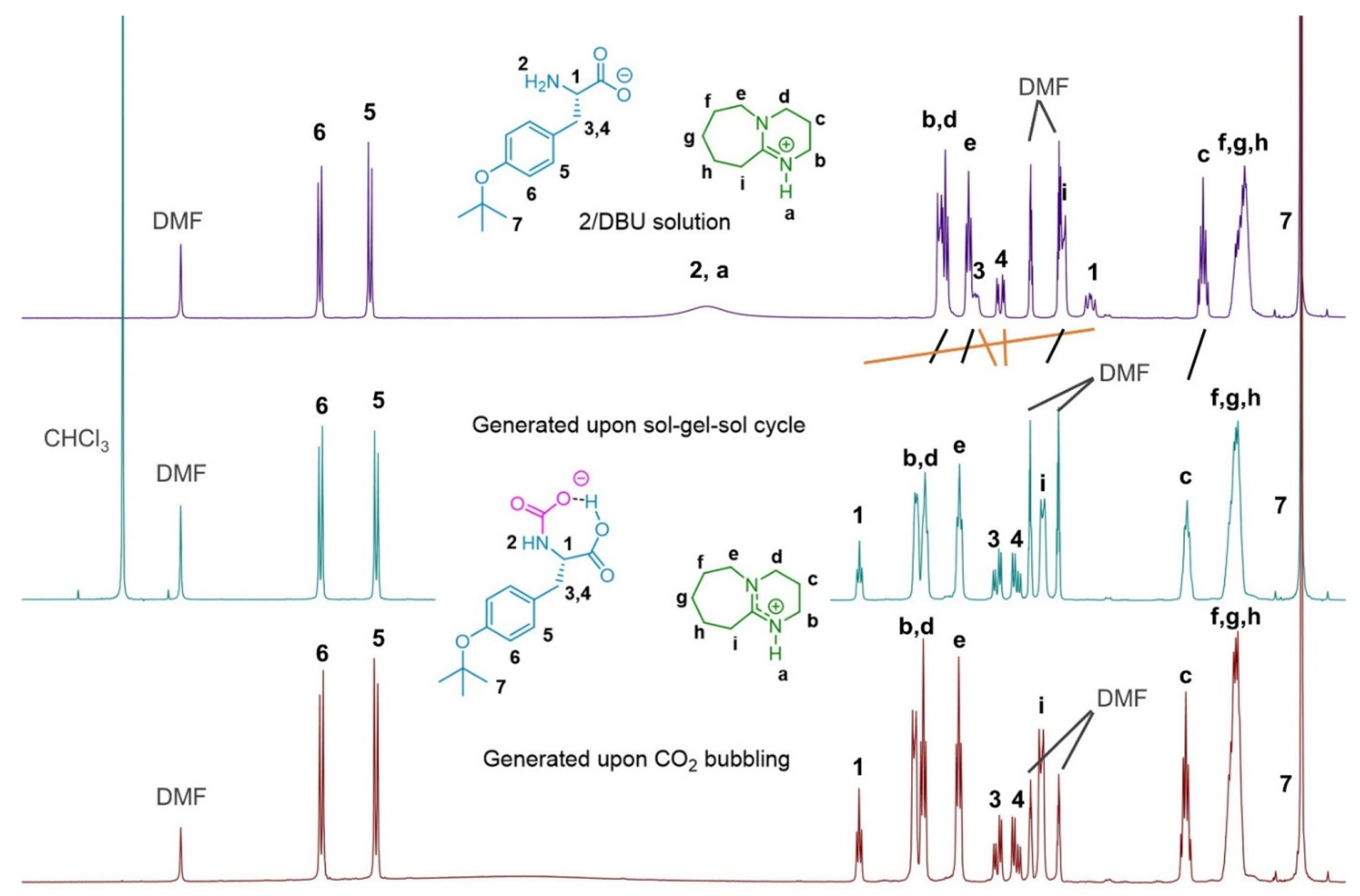

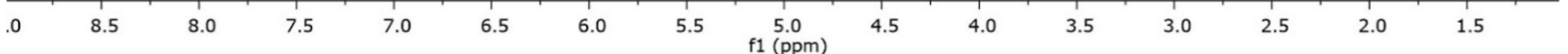

Figure 7. ${ }^{1} \mathrm{H}$ NMR monitoring of the sol-gel-sol cycle in DMF- $d_{7}$. Top: 2/DBU adduct. Middle: solution A after initiation sol-gel-sol cycle. Bottom: 2.DBU. $\mathrm{CO}_{2}$ adduct generated from $\mathrm{CO}_{2}$ bubbling.

step 3. The negative ECD signal being characteristic of the gel, these two steps describe the gel assembly process. During gel formation, a sharp acceleration in gel formation is observed in step 3, probably when a threshold of fiber concentration has been reached. The stages 4 to 5 correspond to a negative plateau in ECD and characterize the lifetime of the gel. The UV shows, however, that during these steps the gel undergoes several small modifications difficult to detect in ECD from step 4 to 5 . Because the ECD signal remains constant, this indicates that these changes are not connected to the supramolecular assembly of the amino acid but more likely to a reorganization between the fibers and the solvent.

This is confirmed through the measure of the turbidity of the gel which increases after multiple cycles, probably through a small accumulation of chloroform and $\mathrm{CO}_{2}$ in the system impacting the interfiber relationship and modifying the dispersion (see Figure S14). This was confirmed by a loss of gelation properties by using the vial inversion method after running 25 cycles, property restored upon residual chloroform, and $\mathrm{CO}_{2}$ removal under reduced pressure (see the Supporting Information). At the end of the cycle, the emergence of liquid in the gel at the macroscopic level can be identified by the increase of the ECD intensity in step 7 until the return to the liquid state characterized in ECD and in the UV by a plateau.
Dissipative System Mechanism. To get a better insight at the molecular level into the structures implied in the sol-gelsol switch, it was studied through ${ }^{1} \mathrm{H}$ NMR spectroscopy. From a 2/DBU adduct DMF- $\mathrm{D}_{7}$ solution (Figure 7, top), TCA was added and the system analyzed upon formation of a new solution resulting from the initiation sol-gel-sol cycle (Figure 7, middle). Formation of chloroform through TCA decarboxylation was confirmed by the appearance of a singlet at $8.33 \mathrm{ppm}$. Proton 1 in the new adduct generated upon the initiation cycle is strongly deshielded from 2.55 to $3.96 \mathrm{ppm}$ as compared to the 2.DBU. According to the literature, this corresponds to a $\mathrm{CO}_{2}$ insertion through carbamate formation, ${ }^{13}$ where the anionic charge might be delocalized between the carboxylic acid and the carbamate. ${ }^{13 \mathrm{~b}}$ This $\mathrm{CO}_{2}$ adduct is stable over time and represents the resting state of the system, generated again upon another sol-gel-sol cycle (Figure S26). The formation of the $\mathrm{CO}_{2}$ adduct was also confirmed by bubbling $\mathrm{CO}_{2}$ to a $2 /$ DBU solution leading to the same spectra (Figure 7, bottom). While such $\mathrm{CO}_{2}$ insertion into amino acids had previously been induced by using $\mathrm{CO}_{2}$ pressure, to our knowledge, it is the first time it is observed through decarboxylation of TCA. This is also in sharp contrast with the precedent literature applications of $\mathrm{TCA}^{9}$ and highly complementary to two-state molecular switches based on $\mathrm{CO}_{2}$ gas fixation. ${ }^{15}$ 
The intermediate generation of protonated 2 and subsequent gel formation could also be monitored by ${ }^{1} \mathrm{H}$ NMR upon TCA addition in the absence of DBU (see Figure S24). From insoluble $\mathbf{2}$ in DMF, TCA addition generates a solution where $\mathbf{2}$ is present under its protonated form before slowly evolving to the neutral gel when all TCA is consumed. $\mathrm{CHCl}_{3}$ formation is observed at $8.33 \mathrm{ppm}$ while peaks corresponding to 2 disappear through fibers formation. These results also confirm that $\mathrm{CO}_{2}$ fixation by $\mathbf{2}$ is only possible in the presence of DBU.

Altogether, these experiments corroborate the three states mechanism shown in Figure 1. The 2.DBU.CO $\mathrm{C}_{2}$ adduct solution A formed upon an initial sol-gel-sol cycle (Scheme S1) corresponds to the resting state of the system. Adding TCA, a strong acid, protonates the carbamate instantaneously, liberating 1 equiv of $\mathrm{CO}_{2}$ as reported in the literature with $\mathrm{CF}_{3} \mathrm{COOH}$. The strong acid also protonates the basic $\mathrm{DBU}$ and 2, providing the acidic solution B. From solution B, upon amine-catalyzed TCA decarboxylation, the liberated neutral amino acid $C$ rapidly self-assembles, creating the strong fibers entrapping the solvent in the gel matrix. As demonstrated in the previous report on $\mathbf{2}$ gelation, ${ }^{12}$ multiple hydrogen-bonding interactions between amines and acids functions as well as attractive van der Waals interactions between the lipophilic tert-butyl groups are responsible for the gelation. ECD analysis of a gel obtained in the absence of DBU also confirmed that the same supramolecular assembly was obtained (see Figure S21). From the gel, 1 equiv of $\mathrm{CO}_{2}$ dissolved in the solvent is trapped by the 2 / DBU combination generating back the initial solution $\mathrm{A}$. In the absence of DBU or when using weaker bases such as $\mathrm{Et}_{3} \mathrm{~N}$, no carbamate formation is observed so that the system remains at the gel state. Given the difference in $\mathrm{p} K_{\mathrm{a}}$ between the strong acid and the basic DBU, the carbamate formation is prevented until all TCA is removed from the system through decarboxylation. Overall, from this mechanism, DBU and TCA concentrations greatly impact both gelation and gel destruction kinetics. As a result of this reactivity pattern, the combination of a primary amine and DBU considerably broadens the possibilities offered by the use of TCA as dissipative fuel.

Rheological Properties. With an optimal system in hand, the rheological properties, a key point for further applications, were also scrutinized (see Figure S33). Upon addition of TCA to a $2 / \mathrm{DBU}$ solution, the transient formation of a gel was clearly observed through the increase in both storage $\left(G^{\prime}\right)$ and loss modulus $\left(G^{\prime \prime}\right)$. From the temporary gel state where $G^{\prime}>G^{\prime \prime}$, both $G^{\prime}$ and $G^{\prime \prime}$ decrease over time until a solution is generated again. Most importantly, the high storage modulus $G^{\prime}(70000$ $\mathrm{Pa}$ ) obtained at the maximum confirms the high resistance of the transiently generated supramolecular structure, corresponding to the results observed through the vial inversion method. From these rheology experiments, a gel is formed with impressive stiffness, and the mechanical properties are relevant for potential real-life applications. We demonstrated this behavior by molding dissipative gel cones (Figure 8, see the Supporting Information for other cones). For example, a $10 \mathrm{~mL}$ dissipative gel cone doped with Congo red as dye could be generated and slowly decomposed back to a solution over $7 \mathrm{~h}$. Of interest, the availability and the price of the different reagents make the system highly affordable for scale-up.

\section{CONCLUSION}

Dissipative gels have the potential to deeply impact the future of smart materials, but the design of simple and robust systems possessing complex defined functions such as enhanced
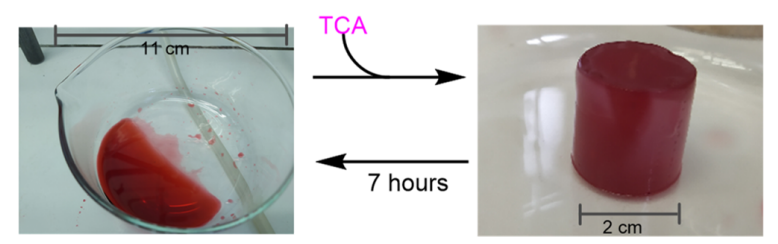

Figure 8. Molding of a $10 \mathrm{~mL}$ DMF cone gel constituted of $43 \mu \mathrm{M} 2,29$ $\mu \mathrm{M} \mathrm{DBU}$, and $159 \mu \mathrm{M}$ TCA. The red color is made by using Congo red as dye.

chiroptical properties is mandatory. In this study, we have been able to develop a new approach to chemically fuel a threestates chiroptical switching supramolecular gel with temporal control. The system is based on the combination between a chiral amino acid and DBU. From an anionic solution, upon addition and subsequent consumption of trichloroacetic acid (TCA) as acidic fuel, the system can switch to cationic and then to neutral gelating form before going back to the anionic resting state. TCA decomposition generates volatile $\mathrm{CHCl}_{3}$ and $\mathrm{CO}_{2}$ removable from the system, while one molecule of $\mathrm{CO}_{2}$ is trapped at the resting state through carbamate formation.

Of utmost importance, thanks to the amino acid chirality, a fully moldable material with chiroptical switching properties moving through three distinct signals is observed as monitored through ECD spectroscopy. As a result, this purely synthetic system considerably enhances the potential of smart molecular materials notably for application in logic gates or data storage. It is simple and robust (over 25 consecutive sol-gel-sol cycles) and triggers extremely complex functions. In contrast to previous acidic fuels, the present approach is relying not only on protonation/deprotonation but also on a structural change of an amine over three states. As a result, by using TCA as fuel, carbamate formation should find great applications in the design of new functional materials, switching devices, or molecular motors.

AUTHOR INFORMATION

\section{Corresponding Author}

Adrien Quintard - Aix Marseille Univ, CNRS, Centrale Marseille, Marseille, France; $\odot$ orcid.org/0000-0003-01936524; Email: adrien.quintard@univ-amu.fr

\section{Authors}

Enzo Olivieri - Aix Marseille Univ, CNRS, Centrale Marseille, Marseille, France

Guilhem Quintard - Université de Lyon, INSA LYON, Ingénierie des Matériaux Polymères IMP-UMR, CNRS, F 69621 Villeurbanne, France

Jean-Valère Naubron - Aix Marseille Univ, CNRS, Centrale Marseille, Marseille, France; $\odot$ orcid.org/0000-0002-85234476 


\section{Funding}

The project leading to this publication has received funding from the Excellence Initiative of Aix-Marseille University A*Midex, a French "Investissements d'Avenir" program" (A-MAAP-EI-17-06-170223-13.06-QUINTARD-SAT). The Centre National de la Recherche Scientifique (CNRS) and AixMarseille Université are warmly acknowledged for financial support.

\section{Notes}

The authors declare no competing financial interest.

\section{ACKNOWLEDGMENTS}

All technical staff from Aix-Marseille Spectropole, notably Roselyne Rosas, and the personal from the microscopy department are acknowledged for their support. Dr. Yoann Coquerel is warmly thanked for discussions and proof-reading. Baptiste Gasch is acknowledged for experimental support. The team Biosciences of the iSm2 is acknowledged for the access to UV spectroscopy instruments.

\section{REFERENCES}

(1) Whitesides, G. M.; Grzybowski, B. Self-Assembly at All Scales. Science 2002, 295, 2418-2421.

(2) For excellent reviews highlighting the known strategies, see: (a) van Rossum, S. A. P.; Tena-Solsona, M.; van Esch, J. H.; Eelkema, R.; Boekhoven, J. Dissipative out-of-equilibrium assembly of man-made supramolecular materials. Chem. Soc. Rev. 2017, 46, 5519-5535. (b) De, S.; Klajn, R. Dissipative Self-Assembly Driven by the Consumption of Chemical Fuels. Adv. Mater. 2018, 30, 1706750. (c) Wang, G.; Liu, S. Strategies to Construct a Chemical-Fuel-Driven Self-Assembly. ChemSystemsChem. 2020, 2, No. e1900046. (d) Leng, Z. J.; Peng, F.; Hao, X. Chemical-Fuel-Driven Assembly in Macromolecular Science: Recent Advances and Challenges. ChemPlusChem. 2020, 85, 1190-1199. (e) Rieß, B.; Grötsch, R. K.; Boekhoven, J. The Design of Dissipative Molecular Assemblies Driven by Chemical Reaction Cycles. Chem. 2020, 6, 552-578. (f) Singh, N.; Formon, G. J. M.; De Piccoli, S.; Hermans, T. M. Devising Synthetic Reaction Cycles for Dissipative Nonequilibrium Self-Assembly. Adv. Mater. 2020, 32, 1906834. For a review on the potential applications, see: $(\mathrm{g})$ Rieß, B.; Boekhoven, J. Applications of Dissipative Supramolecular Materials with a Tunable Lifetime. ChemNanoMat 2018, 4, 710-719.

(3) For examples of dissipative self-assembly based on enzymatic transformations, see: (a) Debnath, S.; Roy, S.; Ulijn, R. V. Peptide Nanofibers with Dynamic Instability through Nonequilibrium Biocatalytic Assembly. J. Am. Chem. Soc. 2013, 135, 16789-16792. (b) Pezzato, C.; Prins, L. J. Transient signal generation in a selfassembled nanosystem fueled by ATP. Nat. Commun. 2015, 6, 77907797. (c) Heuser, T.; Weyandt, E.; Walther, A. Biocatalytic FeedbackDriven Temporal Programming of Self-Regulating Peptide Hydrogels. Angew. Chem., Int. Ed. 2015, 54, 13258-13262. (d) Angulo-Pachon, C. A.; Miravet, J. F. Sucrose-fueled, energy dissipative, transient formation of molecular hydrogels mediated by yeast activity. Chem. Commun. 2016, 52, 5398-5401. (e) Maiti, S.; Fortunati, I.; Ferrante, C.; Scrimin, P.; Prins, L. J. Dissipative self-assembly of vesicular nanoreactors. Nat. Chem. 2016, 8, 725-731. (f) Sahoo, J. K.; Pappas, C. G.; Sasselli, I. R.; Abul-Haija, Y. M.; Ulijn, R. V. Biocatalytic Self-Assembly Cascades. Angew. Chem., Int. Ed. 2017, 56, 6828-6832. (g) Heinen, L.; Heuser, T.; Steinschulte, A.; Walther, A. Antagonistic Enzymes in a Biocatalytic $\mathrm{pH}$ Feedback System Program Autonomous DNA Hydrogel Life Cycles. Nano Lett. 2017, 17, 4989-4995. (h) Che, H.; Buddingh', B. C.; van Hest, J. C. M. Self-Regulated and Temporal Control of a "Breathing" Microgel Mediated by Enzymatic Reaction. Angew. Chem., Int. Ed. 2017, 56, 12581-12585. (i) Hao, X.; Sang, W.; Hu, J.; Yan, Q. Pulsating Polymer Micelles via ATP-Fueled Dissipative Self-
Assembly. ACS Macro Lett. 2017, 6, 1151-1155. (j) Hu, K.; Sheiko, S. S. Time programmable hydrogels: regulating the onset time of network dissociation by a reaction relay. Chem. Commun. 2018, 54, 5899-5902. (k) Mondal, S.; Podder, D.; Nandi, S. K.; Roy Chowdhury, S.; Haldar, D. Acid-responsive fibrillation and urease-assisted defibrillation of phenylalanine: a transient supramolecular hydrogel. Soft Matter 2020, 16, 10115-10121.

(4) The landmark results were obtained by using alkylating reagents: (a) Boekhoven, J.; Brizard, A. M.; Kowlgi, K. N. K.; Koper, G. J. M.; Eelkema, R.; van Esch, J. H. Dissipative self-assembly of a molecular gelator by using a chemical fuel. Angew. Chem., Int. Ed. 2010, 49, 48254828. (b) Boekhoven, J.; Hendriksen, W. E.; Koper, G. J. M.; Eelkema, R.; van Esch, J. H. Transient assembly of active materials fueled by a chemical reaction. Science 2015, 349, 1075-1079. Alternative methods rely on the use of carbodiimide as fuel for anhydride or ester formation generating strongly coordinating urea as waste: (c) Tena-Solsona, M.; Rie $\beta$, B.; Grötsch, R. K.; Löhrer, F. C.; Wanzke, C.; Käsdorf, B.; Bausch, A. R.; Müller-Buschbaum, P.; Lieleg, O.; Boekhoven, J. Nonequilibrium dissipative supramolecular materials with a tunable lifetime. Nat. Commun. 2017, 8, 15895-15903. (d) Bal, S.; Das, K.; Ahmed, S.; Das, D. Chemically Fueled Dissipative Self-Assembly that Exploits Cooperative Catalysis. Angew. Chem., Int. Ed. 2019, 58, 244247. (e) Afrose, S. P.; Bal, S.; Chatterjee, A.; Das, K.; Das, D. Designed Negative Feedback from Transiently Formed Catalytic Nanostructures. Angew. Chem., Int. Ed. 2019, 58, 15783-15787. (f) Zhang, B.; Jayalath, I. M.; Ke, J.; Sparks, J. L.; Hartley, C. S.; Konkolewicz, D. Chemically fueled covalent crosslinking of polymer materials. Chem. Commun. 2019, 55, 2086-2089. (g) Dai, K.; Fores, J. R.; Wanzke, C.; Winkeljann, B.; Bergmann, A. M.; Lieleg, O.; Boekhoven, J. Regulating Chemically Fueled Peptide Assemblies by Molecular Design. J. Am. Chem. Soc. 2020, 142, 14142-14149. For the use of a complex solution of glucose, dithionite, and hexamethylenetetramine: (h) Singh, N.; Lainer, B.; Formon, G. J. M.; De Piccoli, S.; Hermans, T. M. Reprogramming Hydrogel Properties Using a Fuel-Driven Reaction Cycle. J. Am. Chem. Soc. 2020, 142, 4083-4087. Finally, for redox systems for dithiane formation: (i) Wojciechowski, J. P.; Martin, A. D.; Thordarson, P. Kinetically Controlled Lifetimes in Redox-Responsive Transient Supramolecular Hydrogels. J. Am. Chem. Soc. 2018, 140, 2869-2874. (j) Ogden, W. A.; Guan, Z. Redox Chemical-Fueled Dissipative Self-Assembly of Active Materials. ChemSystemsChem. 2020, 2, No. e1900030. (k) Bal, S.; Ghosh, C.; Ghosh, T.; Vijayaraghavan, R. K.; Das, D. Non-Equilibrium Polymerization of Cross-b Amyloid Peptides for Temporal Control of Electronic Properties. Angew. Chem., Int. Ed. 2020, 59, 13506-13510.

(5) For other types of systems applied in non-gelifying self-assembly: (a) Wood, C. S.; Browne, C.; Wood, D. M.; Nitschke, J. R. FuelControlled Reassembly of Metal-Organic Architectures. ACS Cent. Sci. 2015, 1, 504-509. (b) Colomer, I.; Morrow, S. M.; Fletcher, S. P. A transient self-assembling self-replicator. Nat. Commun. 2018, 9, 22392244. (c) Leira-Iglesias, J.; Tassoni, A.; Adachi, T.; Stich, M.; Hermans, T. M. Oscillations, travelling fronts and patterns in a supramolecular system. Nat. Nanotechnol. 2018, 13, 1021-1027. (d) Wang, H.; Wang, Y.; Shen, B.; Liu, X.; Lee, M. Substrate-Driven Transient Self-Assembly and Spontaneous Disassembly Directed by Chemical Reaction with Product Release. J. Am. Chem. Soc. 2019, 141, 4182-4185. (e) Helm, M. P.; Wang, C.-L.; Fan, B.; Macchione, M.; Mendes, E.; Eelkema, R. Organocatalytic Control over a Fuel-Driven Transient-Esterification Network. Angew. Chem., Int. Ed. 2020, 59, 20604-20611.

(6) (a) Feringa, B. L.; van Delden, R. A.; Koumura, N.; Geertsema, E. M. Chiroptical Molecular Switches. Chem. Rev. 2000, 100, 1789-1816. (b) Brandt, J. R.; Salerno, F.; Fuchter, M. J. The added value of smallmolecule chirality in technological applications. Nature Reviews. 2017, 1, 0045. (c) Zhang, L.; Wang, H.-X.; Li, L.; Liu, M. Supramolecular chiroptical switches. Chem. Soc. Rev. 2020, 49, 9095-9120. For a review on logic gates, see: (d) Erbas-Cakmak, S.; Kolemen, S.; Sedgwick, A. C.; Gunnlaugsson, T.; James, T. D.; Yoon, J.; Akkaya, E. U. Molecular logic gates: the past, present and future. Chem. Soc. Rev. 2018, 47, 2228-2248. For data storage, see: (e) Clelland, C. T.; Risca, V.; Bancroft, C. Hidding messages in DNA microdots. Nature 1999, 
399, 533-534. (f) Colquhoun, H.; Lutz, J. F. Information-containing macromolecules. Nat. Chem. 2014, 6, 455-456.

(7) See refs $3 \mathrm{k}, 4 \mathrm{c}-\mathrm{e}$, and $\mathrm{k}$ and for other dissipative systems: (a) Sorrenti, A.; Leira-Iglesias, J.; Sato, A.; Hermans, T. M. Nonequilibrium steady states in supramolecular polymerization. Nat. Commun. 2017, 8, 15899.

(8) (a) Dhiman, S.; Jain, A.; George, S. J. Transient Helicity: FuelDriven Temporal Control over Conformational Switching in a Supramolecular Polymer. Angew. Chem., Int. Ed. 2017, 56, 13291333. (b) Dhiman, S.; Jain, A.; Kumar, M.; George, S. J. AdenosinePhosphate-Fueled, Temporally Programmed Supramolecular Polymers with Multiple Transient States. J. Am. Chem. Soc. 2017, 139, 1656816575. (c) Li, Z.; Zeman, C. J., IV; Valandro, C. R.; Bantang, J. P. O.; Schanze, K. S. Adenosine Triphosphate Templated Self-Assembly of Cationic Porphyrin into Chiral Double Superhelices and EnzymeMediated Disassembly. J. Am. Chem. Soc. 2019, 141, 12610-12618.

(9) (a) Brown, B. R. The mechanism of thermal decarboxylation. $Q$. Rev., Chem. Soc. 1951, 5, 131-146. (b) Abe, Y.; Okamura, H.; Nakazono, K.; Koyama, Y.; Uchida, S.; Takata, T. Thermoresponsive Shuttling of Rotaxane Containing Trichloroacetate Ion. Org. Lett. 2012, 14, 4122-4125. (c) Zhu, N.; Nakazono, K.; Takata, T. Solid-state Rotaxane Switch: Synthesis of Thermoresponsive Rotaxane Shuttle Utilizing a Thermally Decomposable Acid. Chem. Lett. 2016, 45, 445447. (d) Erbas-Cakmak, S.; Fielden, S. D. P.; Karaca, U.; Leigh, D. A.; McTernan, C. T.; Tetlow, D. J.; Wilson, M. R. Rotary and linear molecular motors driven by pulses of a chemical fuel. Science 2017, 358, 340-343. (e) Biagini, C.; Fielden, S. D. P.; Leigh, D. A.; Schaufelberger, F.; Di Stefano, S.; Thomas, D. Dissipative Catalysis with a Molecular Machine. Angew. Chem., Int. Ed. 2019, 58, 9876-9880. (f) Choi, S.; Mukhopadhyay, R. D.; Kim, Y.; Hwang, I.-C.; Hwang, W.; Ghosh, S. K.; Baek, K.; Kim, K. Fuel-Driven Transient Crystallization of a Cucurbit[8]uril-Based Host-Guest Complex. Angew. Chem., Int. Ed. 2019, 58, 16850-16853.

(10) For other examples of dissipative molecular switches based on acid consumption: (a) Berrocal, J. A.; Biagini, C.; Mandolini, L.; Di Stefano, S. Coupling of the Decarboxylation of 2-Cyano-2-phenylpropanoic Acid to Large-Amplitude Motions: A Convenient Fuel for an Acid-Base-Operated Molecular Switch. Angew. Chem., Int. Ed. 2016, 55, 6997-7001. (b) Ghosh, A.; Paul, I.; Adlung, M.; Wickleder, C.; Schmittel, M. Oscillating Emission of [2]Rotaxane Driven by Chemical Fuel. Org. Lett. 2018, 20, 1046-1049. For a recent review, see: (c) Biagini, C.; Di Stefano, S. Abiotic Chemical Fuels for the Operation of Molecular Machines. Angew. Chem., Int. Ed. 2020, 59, 8344-8354.

(11) (a) Jayawarna, V.; Ali, M.; Jowitt, T. A.; Miller, A. F.; Saiani, A.; Gough, J. E.; Ulijn, R. V. Nanostructured Hydrogels for ThreeDimensional Cell Culture Through Self-Assembly of Fluorenylmethoxycarbonyl-Dipeptides. Adv. Mater. 2006, 18, 611-614. (b) Tang, C.; Ulijn, R. V.; Saiani, A. Effect of Glycine Substitution on FmocDiphenylalanine Self-Assembly and Gelation Properties. Langmuir 2011, 27, 14438-14449.

(12) Aykent, G.; Zeytun, C.; Marion, A.; Özçubukçcu, S. Simple Tyrosine Derivatives Act as Low Molecular Weight Organogelators. Sci. Rep. 2019, 9, 4893-4900.

(13) (a) Pérez, E. R.; da Silva, M. O.; Costa, V. C.; Rodrigues-Filho, U. P.; Franco, D. W. Efficient and clean synthesis of N-alkyl carbamates by transcarboxylation and $\mathrm{O}$-alkylation coupled reactions using a DBU$\mathrm{CO}_{2}$ zwitterionic carbamic complex in aprotic polar media. Tetrahedron Lett. 2002, 43, 4091-4093. (b) Ethier, A. E.; Switzer, J. R.; Rumple, E. C.; Medina-Ramos, W.; Li, Z.; Fisk, J.; Holden, B.; Gelbaum, L.; Pollet, P.; Eckert, C. E.; Liotta, C. L. The Effects of Solvent and Added Bases on the Protection of Benzylamines with Carbon Dioxide. Processes 2015, 3, 497-513. (c) Carrera, G. V. S. M.; Jordao, N.; Santos, M. M.; da Ponte, M. N.; Branco, L. C. Reversible systems based on $\mathrm{CO}_{2}$, amino-acids and organic superbases. RSC Adv. 2015, 5, 35564-35571. (d) Biancalana, L.; Bresciani, G.; Chiappe, C.; Marchetti, F.; Pampaloni, G. Synthesis and study of the stability of amidinium/ guanidinium carbamates of amines and a-amino acids. New J. Chem. 2017, 41, 1798-1805.
(14) We found that $\mathbf{2}$ in itself is not soluble enough to induce gelation in DMF unless DMSO is added to help solubilize $\mathbf{2}$ (see the Supporting Information). It is likely that the ultrasound heat bath used in ref 12 helps breaking this zwitterionic structure to induce gelation. In the present system, TCA solubilizes 2 by breaking the zwitterionic form through amine protonation and subsequent return to the neutral form through TCA decarboxylation.

(15) (a) George, M.; Weiss, R. G. Chemically Reversible Organogels: Aliphatic Amines as "Latent" Gelators with Carbon Dioxide. J. Am. Chem. Soc. 2001, 123, 10393-10394. (b) Yamada, T.; Lukac, P. J.; George, M.; Weiss, R. G. Reversible, Room-Temperature Ionic Liquids. Amidinium Carbamates Derived from Amidines and Aliphatic Primary Amines with Carbon Dioxide. Chem. Mater. 2007, 19, 967-969. (c) Mukhopadhyay, R. D.; Choi, S.; Sen, S. K.; Hwang, I.-C.; Kim, K. Transient Self-assembly Processes Operated by Gaseous Fuels under Out-of-Equilibrium Conditions. Chem. - Asian J. 2020, 15, 4118-4123.

(16) As observed from the literature, from a carbamate, addition of a strong acid such as TFA instantaneously removes $\mathrm{CO}_{2}$ : Al-Terkawi, A.A.; Lamaty, F.; Métro, T.-X. Efficient $\mathrm{CO}_{2}$ Sequestration by a SolidGas Reaction Enabled by Mechanochemistry: The Case of L-Lysine. ACS Sustainable Chem. Eng. 2020, 8, 13159-13166. 